\title{
Perancangan dan Pengembangan Permainan Jelajah Indonesia Berbasis iOS Menggunakan GameSalad
}

\author{
Arsi Kurniawan, Kodrat Iman Satoto ${ }^{2)}$, Rinta Kridalukmana ${ }^{2)}$ \\ Program Studi Sistem Komputer Fakultas Teknik Universitas Diponegoro \\ Jalan Prof. Sudharto, Tembalang, Semarang, Indonesia \\ arsikurn@gmail.com
}

\begin{abstract}
Indonesia is the largest archipelago in the world is made up of thousands of islands. Even in each island, the Indonesian people have a variety of ethnic, regional languages and different customs. And of course in every region in Indonesia has the characteristic of each, ranging from traditional foods, folk song, a mainstay of tourism, and unique customs. It is inevitable because of the vast territory of Indonesia and the many traits that exist in each region as mentioned above, it is no wonder that most Indonesian people themselves do not know the area well characteristic of their own region and other areas. Therefore, it is developing the game Exploration of Indonesia as a medium to introduce the characteristic of regions in Indonesia is through game-based mobile devices iOS.

The game is built using GameSalad. Multimedia development method that used is the Multimedia Development Life Cycle (MDLC) from initial concept through distribution determination. For the method of application testing using Black Box Test.

The results of this study in the form of an application with the name of the game Exploration of Indonesia that can run well on iOS-based mobile devices. This games can be a media campaign for characteristic of regions in Indonesia, both for citizens of Indonesia itself or to a foreign national who indirectly promote Indonesia to the international
\end{abstract}

Keywords : regions characteristic, game, Multimedia Development Life Cycle (MDLC) mobile devices, iOS, GameSalad

\section{PENDAHULUAN}

Saat ini, Indonesia telah menjadi pasar gadget terbesar khususnya di Asia Tenggara. Hal itu terbukti yang dari survei pasar terbaru memperlihatkan bahwa tingkat pembelian smartphone di Indonesia pada tahun 2013 adalah salah satu yang tertinggi di wilayah ini. Berdasarkan survei yang dilakukan oleh Gfk Asia, pada kuartal pertama tahun 2013, masyarakat Indonesia telah membeli sebanyak 14,8 juta smartphone dengan nilai mencapai 3,33 miliar USD. Raihan itu jauh melebihi dua negara Asia Tenggara lain yaitu Thailand dan Malaysia yang masing-masing menjual 7,2 juta unit dan 6,4 juta unit smartphone ${ }^{[1]}$.

Perkembangan game di dunia semakin pesat, khususnya mobile game. Mobile game saat ini sudah menjadi alternatif hiburan bagi semua kalangan baik tua, muda, pria maupun wanita. Hal ini membuat para developer game memiliki kesempatan dan peluang yang sangat besar ${ }^{[2]}$.

Peningkatan permintaan pasar membuat perkembangan mobile game jauh lebih pesat jika dibandingkan dengan game
PC. Developer lebih memilih untuk mengembangkan mobile game karena pasar mobile game yang lebih mudah untuk dijangkau karena perangkat mobile sudah bukan menjadi hal yang asing bagi masyarakat, bahkan perangkat mobile sudah menjadi bagian dari keseharian masyarakat apalagi di kalangan remaja dan biaya yang cenderung lebih rendah dibandingkan dengan game console ${ }^{[3]}$.

Indonesia merupakan negara kepulauan terbesar di dunia yang terbentang di khatulistiwa sepanjang 3200 mil (5.120 km2) dan terdiri atas 13.667 pulau besar dan kecil. Nama Indonesia berasal dari bahasa Yunani, yaitu Indo yang berarti Hindia dan Nesos yang berarti kepulauan. Indonesia juga merupakan $1 / 5$ populasi terbesar di dunia dengan penduduk yang berasal dari ras Melayu dan Polinesia serta terdiri dari 300 suku dan cabangnya yang masing-masing suku memiliki tradisi sendiri. ${ }^{[4]}$.

Tidak dapat dipungkiri karena luas wilayah Indonesia dan banyaknya ciri disetiap daerah, maka tidak heran jika kebanyakan warga Indonesia sendiri tidak mengetahui ciri khas daerah baik daerahnya sendiri maupun daerah lainnya. Maka dibangunlah permainan bertemakan ciri khas yang ada di Indonesia ini yang diharapkan dapat membuat masyarakat Indonesia lebih mengenal karakter negaranya sendiri dengan cara yang menarik.

\section{LANDASAN TEORI}

A. Permainan

Game atau permainan merupakan suatu sistem yang memiliki aturan-aturan tertentu dimana pemain akan terlibat di dalam suatu permasalahan sehingga dapat menghasilkan suatu hasil yang dapat diukur yaitu menang atau kalah. Permainan merupakan sesuatu hal yang dimainkan dengan suatu aturan tertentu yang biasa digunakan untuk tujuan kesenangan dan dapat juga digunakan untuk tujuan pendidikan. Permainan umumnya melibatkan stimulasi mental, fisik, atau keduanya. Banyak permainan yang dapat membantu mengembangkan keterampilan praktis yang berfungsi sebagai latihan, atau melakukan peran pendidikan, simulational, atau psikologis ${ }^{[5]}$.

\section{B. Kebudayaan Indonesia}

Kebudayaan berasal dari kata sansekerta buddayah, yang merupakan bentuk jamak dari buddhi, yang berarti budi atau akal. Dengan demikian, kebudayaan berarti hal-hal yang bersangkutan dengan akal. Adapun ahli antropologi yang 
merumuskan definisi tentang kebudayaan secara sistematis dan ilmiah adalah Taylor, yang menulis dalam bukunya: "Primitive Culture", bahwa kebudayaan adalah keseluruhan yang kompleks, yang di dalamnya terkandung ilmu pengetahuan, kepercayaan, kesenian, moral, hukum, adatistiadat, dan kemampuan lain, serta kebiasaan yang di dapat oleh manusia sebagai anggota masyarakat ${ }^{[8]}$

\section{Multimedia}

Sebuah sistem multimedia dapat digambarkan seperti pada gambar 1 [11]

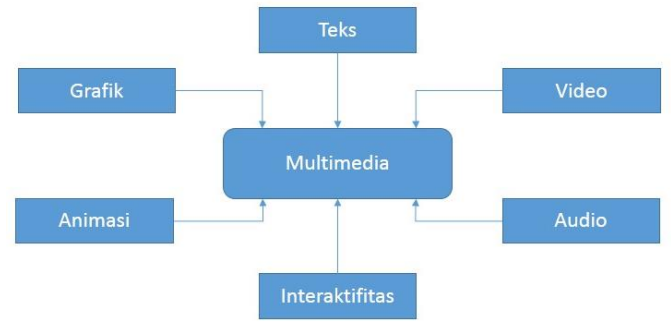

Gambar 1. Gambaran multimedia.

D. Metodologi Pengembangan Mutimedia

Metodologi yang digunakan adalah Multimedia Development Life Cycle (MDLC) yang bersumber dari Luther dan sudah dimodifikasi oleh Sutopo. Metodologi pengembangan multimedia tersebut terdiri dari enam tahap, yaitu konsep (concept), desain (design), pengumpulan materi (material collecting), pembuatan (assembly), pengujian (testing), dan distribusi (distribution). [11]. Tahapan pengembangan multimedia ditunjukkan oleh Gambar 2.

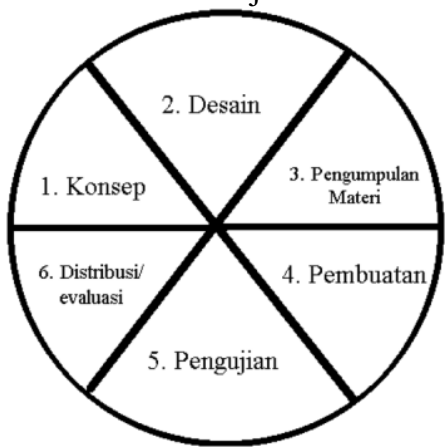

Gambar 2. Tahapan pengembangan multimedia

\section{E. GameSalad}

GameSalad merupakan mesin pengembangan game dengan grafis 2D yang baik untuk iOS. Menurut pihak GameSalad, lebih dari 3\% dari game di App Store diciptakan dengan GameSalad Creator, yang merupakan sebuah development tool. GameSalad Creator telah diunduh lebih dari 150.000 kali sejak tahun 2009. ${ }^{[12]}$

F. iOS

Pada mulanya bernama iPhone OS, namun sejak 7 Juni 2010, Apple mengganti namanya menjadi iOS. iOS adalah sistem operasi yang dipakai oleh iPhone. Aplikasi yang akan kita buat berjalan di atasnya. Fungsinya sangaat sentral, yaitu menjalankan semua komponen yang ada dalam perangkat iPhone, baik perangkat keras maupun perangkat lunak. Sistem operasi ini juga akan melindungi perangkat ketika aplikasi yang kita buat tidak stabil/ $\operatorname{crash}^{[13]}$.

G. Diagram Alir
Diagram alir adalah bagan-bagan yang mempunyai arus yang menggambarkan langkah-langkah penyelesaian suatu masalah. Diagram alir merupakan cara penyajian dari suatu algoritma [16]

\section{H. Adobe Photoshop CS6}

Adobe Photoshop adalah perangkat lunak atau software yang digunakan untuk mengedit foto atau citra yang dibuat oleh perusahaan Adobe Systems. Adobe adalah perusahaan asal Amerika Serikat yang didirikan sejak tahun 1982 dan berkantor di San Jose, California. Pendiri Adobe adalah John Warnock dan Charles Geschke yang pernah bekerja di Xerox PARC. Mereka berhenti saat memutuskan untuk mengembangkan dan menjual bahasa deskripsi PostScript yang menjadi cikal bakal dari Portable Document Format (PDF) ${ }^{[18]}$

\section{Pixen}

Pixen adalah pixel art editor yang dirancang untuk bekerja dengan seni raster beresolusi rendah, seperti sprite 8 bit yang ditemukan di video game-video game jaman dulu. Dengan fitur-fitur inovatif seperti sistem palet warna, pola, dan dukungan perbesaran piksel yang tinggi, Pixen merupakan paket lengkap semua kebutuhan yang diperlukan seniman pixel dalam antarmuka yang intuitif. Pixen juga membuat frame demi frame animasi secara menyenangkan dan mudah. ${ }^{[19]}$

\section{J. Figure}

Figure adalah aplikasi musik yang menyenangkan, menginspirasi dan mengagumkan untuk iPhone, iPad dan iPad mini. Antarmuka yang rapi membuatnya mudah untuk digunakan dalam waktu yang singkat, dan Anda bahkan tidak perlu tahu bagaimana cara memainkan alat musik. [20]

\section{PERANCANGAN SISTEM}

\section{A. Tahapan Pengembangan Multimedia}

1. Konsep

Permainan yang dibuat dapat menjadi media promosi yang interaktif untuk mengenalkan berbagai ciri khas yang berada di beberapa daerah di Indonesia, ciri khas yang dimaksud meliputi: makanan khas, tempat pariwisata, dan tradisi/kesenian/permainan tradisional. Dengan mengenal ciri khas daerah-daerah di negara sendiri dapat meningkatkan kesadaran masyarakat Indonesia akan kekayaan potensi pariwisata Indonesia, sehingga diharapkan dapat meningkatkan kegiatan wisata domestik di Indonesia oleh warganya sendiri. Permainan hanya meliputi 5 pulau yang ada di Indonesia, yakni: Jawa, Sumatera, Kalimantan, Sulawesi, dan Papua.

2. Desain

Tahap awal dalam desain dibuat sebuah bagan struktur menu yang berisi bagian-bagian menu dari aplikasi. Bagan struktur menu ditunjukkan oleh Gambar 3. 


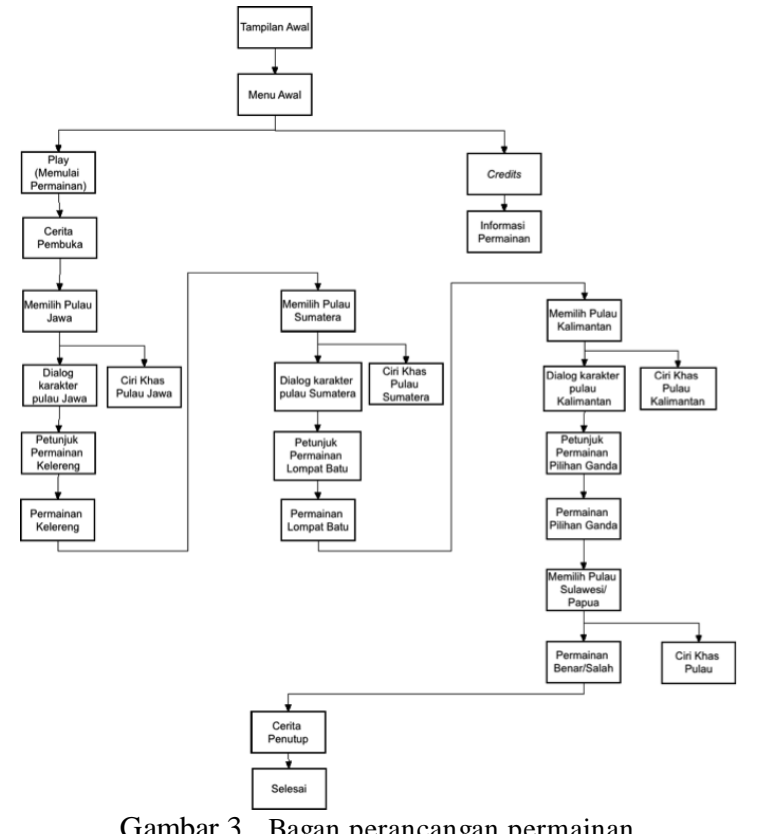

Gambar 3. Bagan perancangan permainan

Setelah dibuat diagram alir untuk mengetahui alur program, selanjutnya dibuat desain tampilan aplikasi. Tampilan menu awal ditunjukkan oleh Gambar 4.

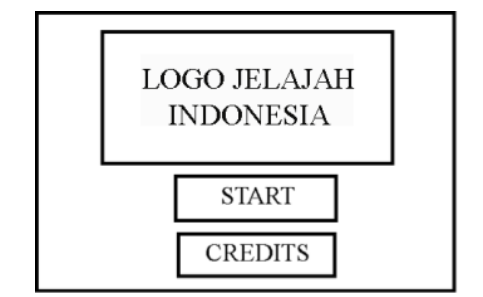

Gambar 4. Desain tampilan menu awal

Desain tampilan menu Credits ditunjukkan oleh Gambar 5.

\begin{tabular}{|c|}
\hline Credits \\
\hline Informasi Pengembang Permainan \\
\hline Informasi Dosen Pembimbing \\
\hline $\begin{array}{c}\text { Informasi Tautan Sumber } \\
\text { Budaya Indonesia }\end{array}$ \\
\hline
\end{tabular}

Gambar 5. Desain tampilan menu Credits

Desain tampilan pilih pulau tujuan ditunjukkan oleh Gambar 6.

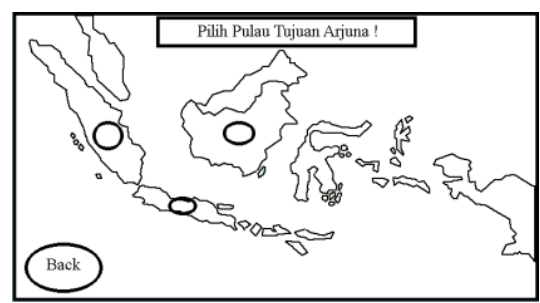

Gambar 6. Desain tampilan Pilih Pulau Tujuan.
Desain tampilan Menu Pulau ditunjukkan oleh Gambar 7.

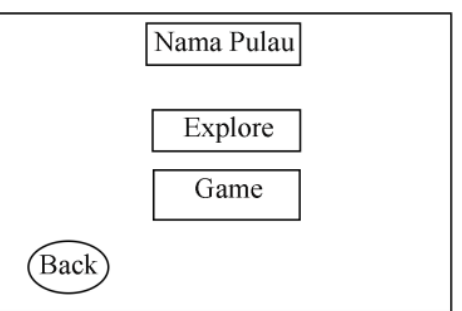

Gambar 7. Desain tampilan Menu Pulau.

Desain tampilan Explore Pulau ditunjukkan oleh Gambar 8

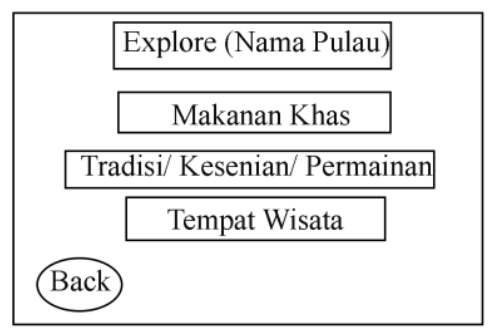

Gambar 8. Desain tampilan Explore Pulau.

Desain tampilan Slideshow Materi Ciri Khas Pulau ditunjukkan oleh Gambar 9.

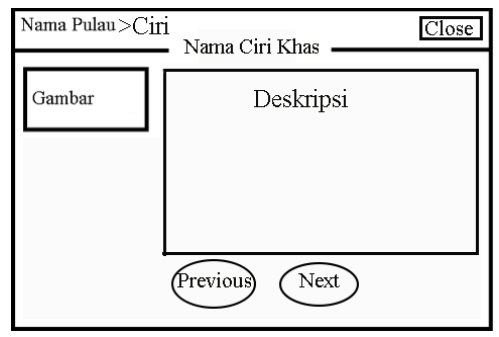

Gambar 9. Desain tampilan Slideshow materi Ciri Khas Pulau

Desain tampilan Percakapan Antar Karakter ditunjukkan oleh Gambar 10.

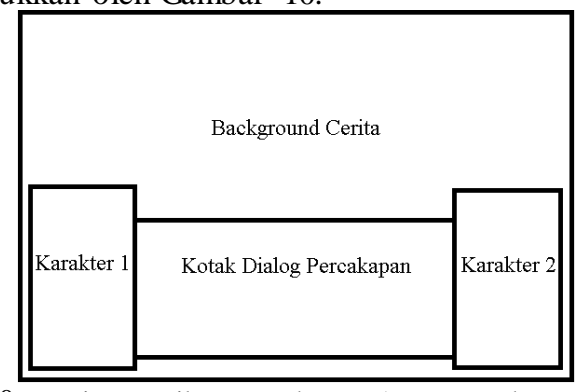

Gambar 10.Desain tampilan Percakapan Antar Karakter. 
Desain tampilan Petunjuk Permainan ditunjukkan oleh Gambar 11.

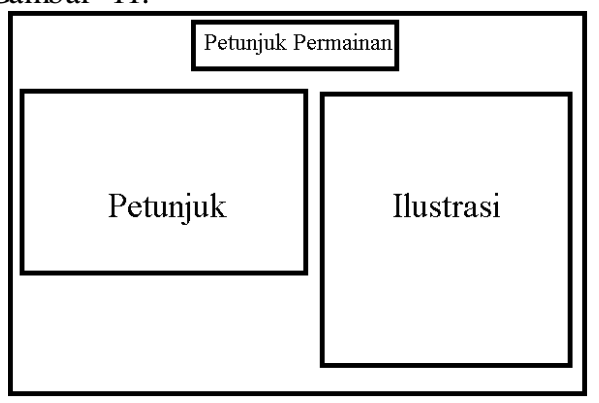

Gambar 11.Desain tampilan Petunjuk Permainan.

Desain tampilan Permainan Kelereng ditunjukkan oleh Gambar 12.

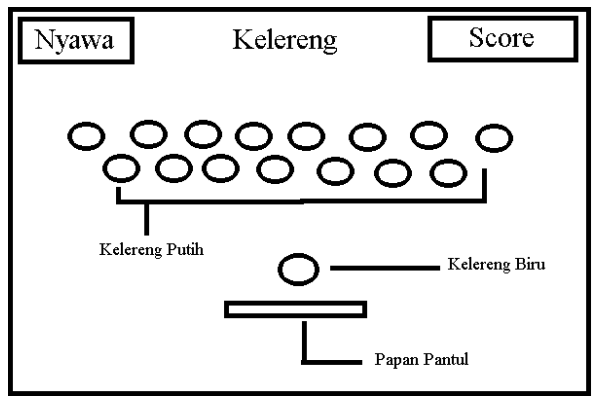

Gambar 12.Desain tampilan Permainan Kelereng.

Desain tampilan Permainan Lompat Batu ditunjukkan oleh Gambar 13.

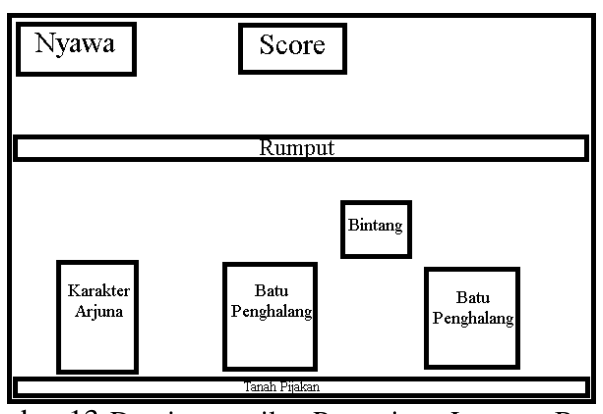

Gambar 13.Desain tampilan Permainan Lompat Batu.

Desain tampilan Permainan Pilihan Ganda ditunjukkan oleh Gambar 14.

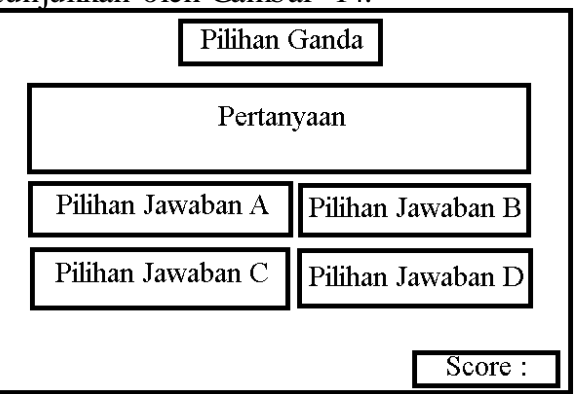

Gambar 14.Desain tampilan Permainan Pilihan Ganda.

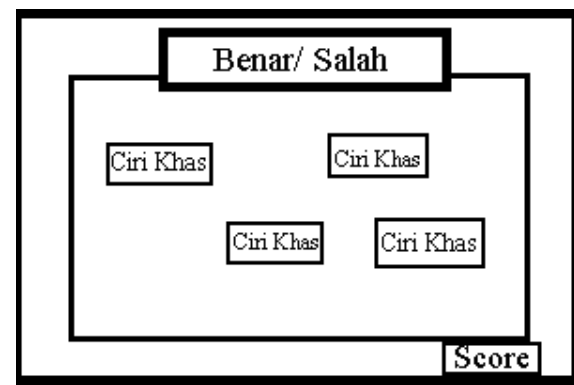

Gambar 15.Desain Tampilan Permainan Benar/Salah

Desain tampilan You Win ditunjukkan oleh Gambar 16.

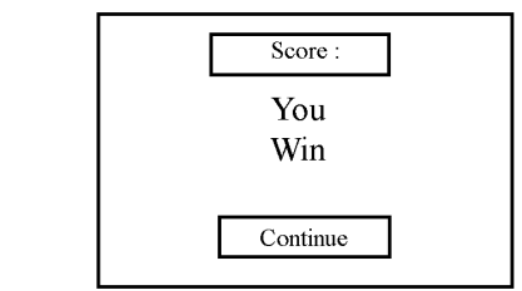

Gambar 16. Desain tampilan You Win

Desain tampilan Game Over ditunjukkan oleh Gambar 17.

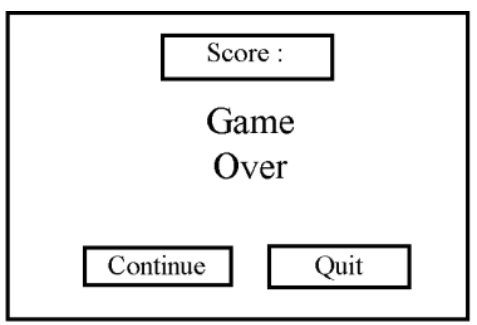

Gambar 17.Desain tampilan Game Over.

Desain tampilan cerita pembuka dan penutup permainan ditunjukkan oleh Gambar 18.

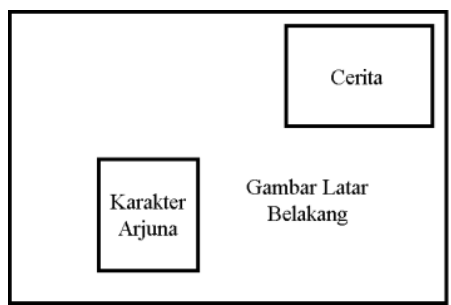

Gambar 18. Desain tampilan cerita pembuka dan penutup permainan.

\section{Pengumpulan Materi}

Dalam tahap ini dilakukan pengumpulan materi perangkat keras yang akan dibahas sesuai dengan kurikulum yang digunakan di Sekolah Menengah Atas. Selain itu, pengumpulan foto, gambar, video, audio yang digunakan untuk bahan pembuatan media pembelajaran.

Desain tampilan Permainan Benar/Salah

ditunjukkan oleh Gambar 3.15. 
4. Pembuatan

Alat dan bahan yang digunakan dalam pembuatan multimedia pembelajaran ini adalah sebagai berikut.

a. Perangkat keras

- PC (Personal Computer) atau Laptop

- Smartphone

b. Perangkat lunak

- OS X versi 10.10 Yosemite

- GameSalad

- Adobe Photoshop CS6

- Pixen

- Figure

\section{Pengujian}

Pada tahap ini dilakukan pengujian permainan, apakah permainan yang dibuat sudah sesuaidengan perancangan dan kebutuhan atau belum. Pengujian pada pembuatan aplikasi ini menggunakan pengujian Black-Box Test. Setelah tahap pengujian ini selesai dan permainan sudah selesai maka dilanjutkan pada tahap terakhir yaitu distribusi/evaluasi.

\section{Distribusi}

Dalam tahap distribusi ini aplikasi telah siap didistribusikan melalui App Store, yang merupakan layanan distribusi konten digital yang disediakan oleh Apple untuk pengguna devices berbasis iOS, sedangkan dari segi evaluasi dilakukan pengujian permainan kepada para pengguna dan meminta pengguna menilai permainan dengan mengisi kuosioner.

\section{HASIL DAN PEMBAHASAN}

A. Hasil pembuatan permainan Jelajah Indonesia

Berikut merupakan tampilan permainan yang sudah dibuat.

1. Tampilan awal permainan

Ketika aplikasi ini pertama dijalankan maka akan terlihat nama lengkap pengembang aplikasi, NIM pengembang, dan disertai karikatur wajah pengembang aplikasi. Tampilan awal permainan ditunjukkan oleh Gambar 19.

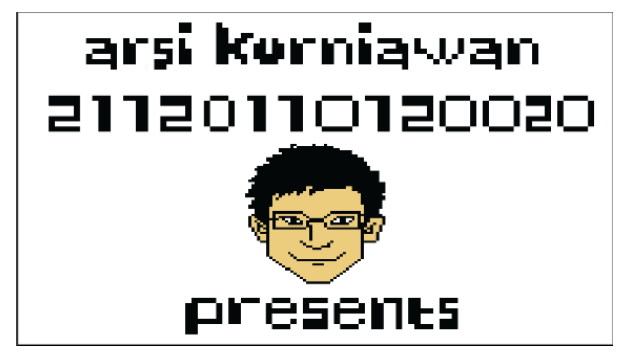

Gambar 19.Tampilan awal permainan

\section{Tampilan Menu awal}

Permainan ini mempunyai 2 menu utama, yakni menu Play dan Credits, Didalam menu Credits akan ditampilkan informasi seputar permainan. Sedangkan menu Play memiliki 3 permainan utama, yakni: Permainan Kelereng, Permainan Lompat Batu, dan Permainan Pilihan Ganda. Tampilan menu awal ditunjukkan oleh Gambar 20.

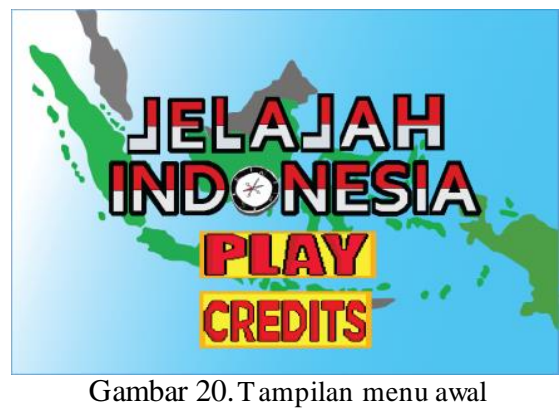

3. Tampilan menu Credits

Di dalam menu Credits akan ditampilkan informasi seputar permainan, seperti: identitas pengembang permainan, dosen pembimbing pengembang, dan tautan-tautan sumber materi ciri khas Indonesia ditunjukkan oleh Gambar 21.

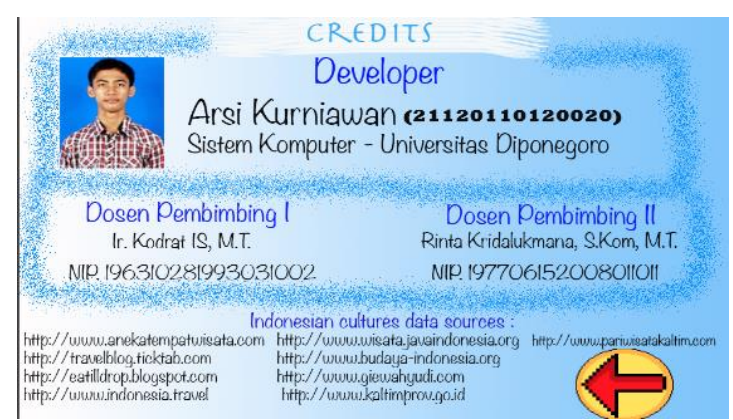

Gambar 21.Tampilan menu Credits

\section{Cerita Pembuka Permainan}

Pada awal Cerita Pembuka Permainan akan diawali perkenalan dengan tokoh utama permainan, yakni : Arjuna, yang kemudian dilanjutkan cerita pendek yang menjadi latar belakang permainan. Tampilan menu Cerita Pembuka Permainan ditunjukkan oleh Gambar 22.

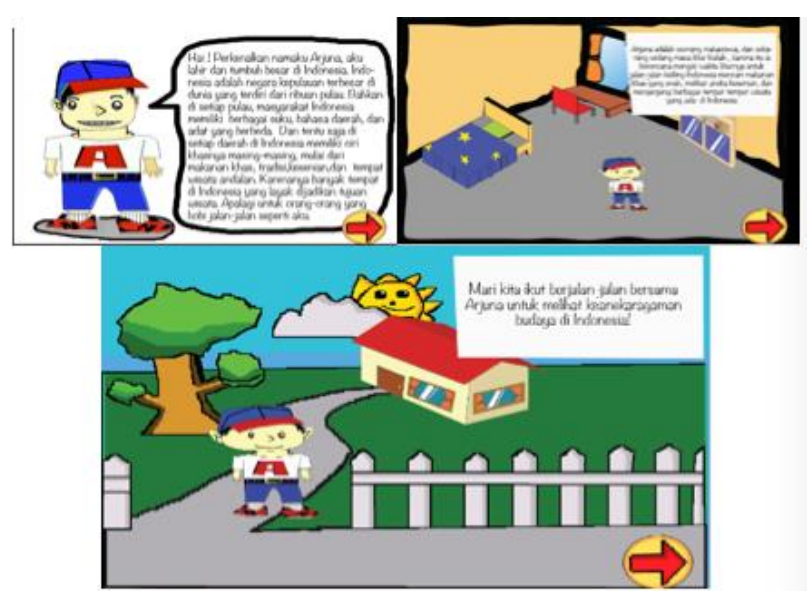

Gambar 22. Tampilan menu Cerita Pembuka Permainan

5. Tampilan Pilih Pulau Tujuan

Setiap memulai level baru dalam permainan. Pemain akan melihat tampilan peta Indonesia, dan pulau tujuan yang akan membawa pemain ke permainan ditandai 
dengan lingkaran kecil yang berkedip. Tampilan Pilih Pulau Tujuan ditunjukkan oleh Gambar 23

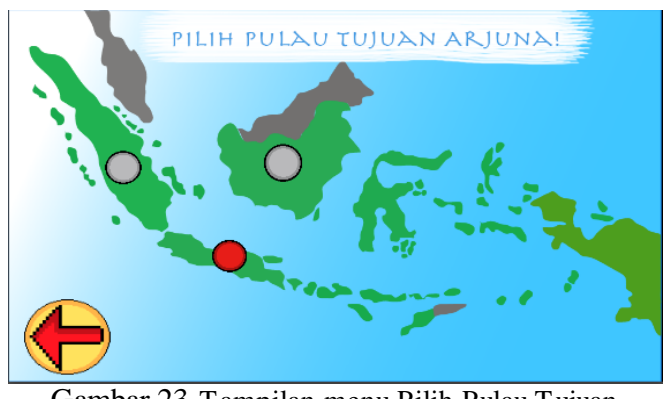

Gambar 23.Tampilan menu Pilih Pulau Tujuan

6. Menu Pulau

Setelah memilih pulau tujuan, tampilan selanjutnya adalah 2 pilihan menu dari pulau tersebut, yakni: explore dan game. Tampilan Menu Pulau ditunjukkan oleh Gambar 24.

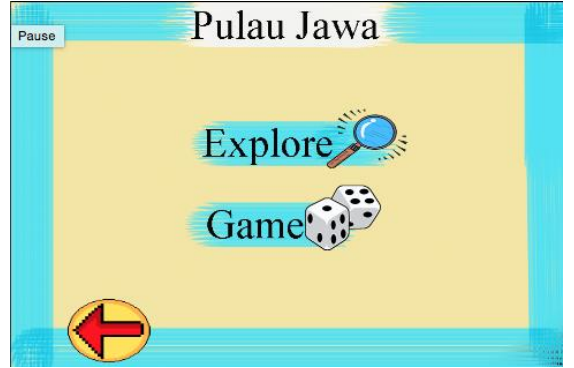

Gambar 24. Tampilan Slideshow materi Ciri Khas Pulau

7. Explore Pulau

Jika pemain memilih explore dalam tampilan Menu Pulau, maka pemain akan dibawa menuju tampilan Explore Pulau. Disini pemain dihadapkan dengan 3 pilihan menu ciri khas daerah pulau yang dipilih. Tampilan menu Explore Pulau ditunjukkan oleh Gambar 25.

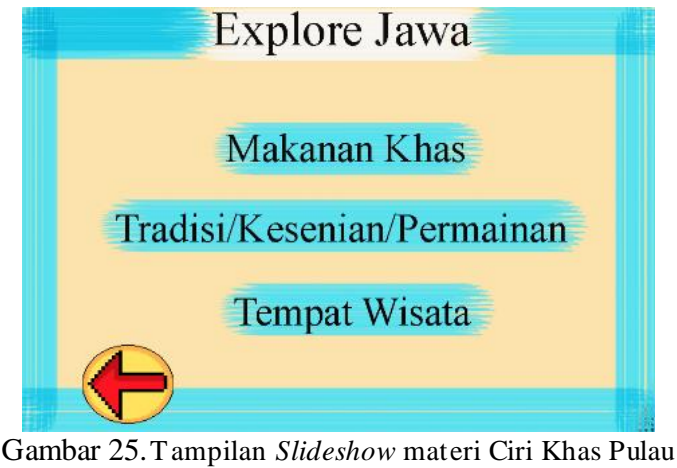

8. Slideshow Materi Ciri Khas Pulau

Setelah memilih pulau tujuan, tampilan selanjutnya adalah slideshow materi ciri khas dari pulau tersebut. Tampilan menu slideshow materi ciri khas pulau ditunjukkan oleh Gambar 26.

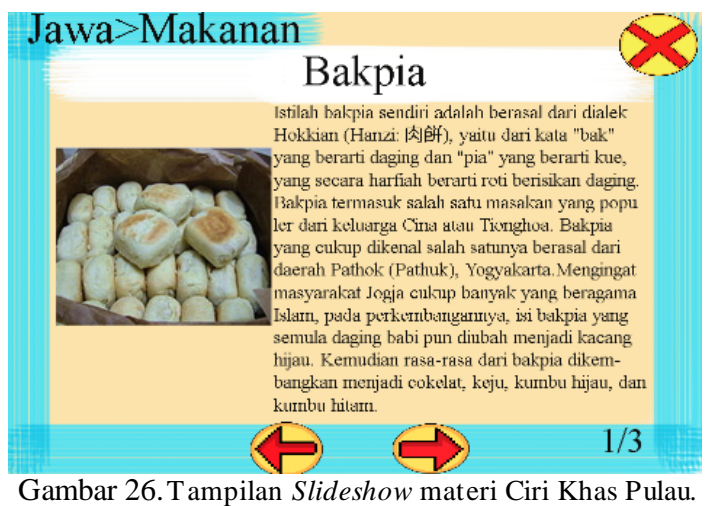

9. Percakapan Antar Karakter

Setelah memilih game di dalam tampilan Menu Pulau, pemain akan dibawa menuju tampilan dialog antara tokoh utama Arjuna dengan satu tokoh yang berasal dari daerah yang sedang dimainkan. Tampilan menu dari Percakapan Antar Karakter ditunjukkan oleh Gambar 27.

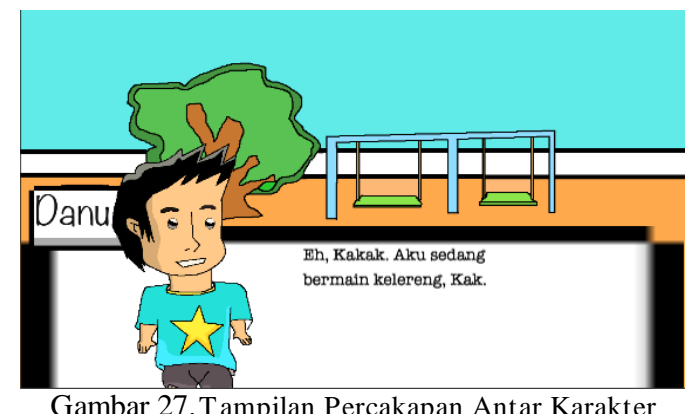

10. Tampilan Petunjuk Permainan

Setelah percakapan antar karakter selesai. Maka akan ditampilkan Petunjuk Permainan yang berkaitan dengan petunjuk cara bermain. Tampilan isi Petunjuk Permainan ditunjukkan oleh Gambar 28

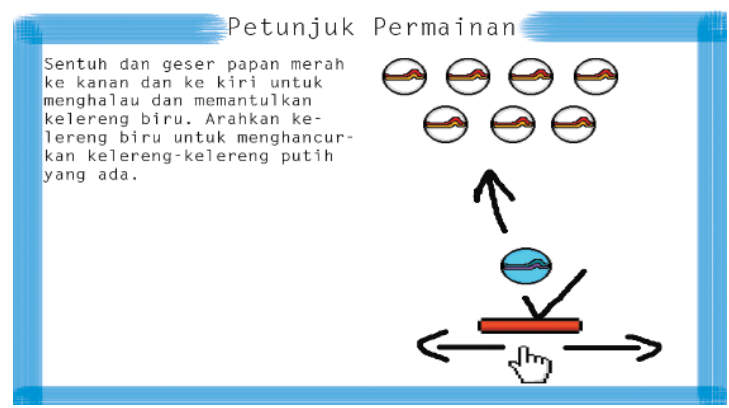

Gambar 28.Tampilan Petunjuk Permainan

\section{Permainan Kelereng}

Setelah melihat petunjuk permainan, tampilan akan otomatis berpindah ke tampilan permainan yang sesungguhnya, permainan yang pertama adalah Permainan Kelereng. Cara bermainnya sederhana, gunakan papan pantul berwarna merah untuk menghalau kelereng biru, arahkan kelereng biru untuk menghancurkan kelereng-kelereng puth yang ada, pemain akan memenangkan permainan jika seluruh kelereng putih sudah dihancurkan. Tampilan Permainan Kelereng ditunjukkan oleh Gambar 29. 


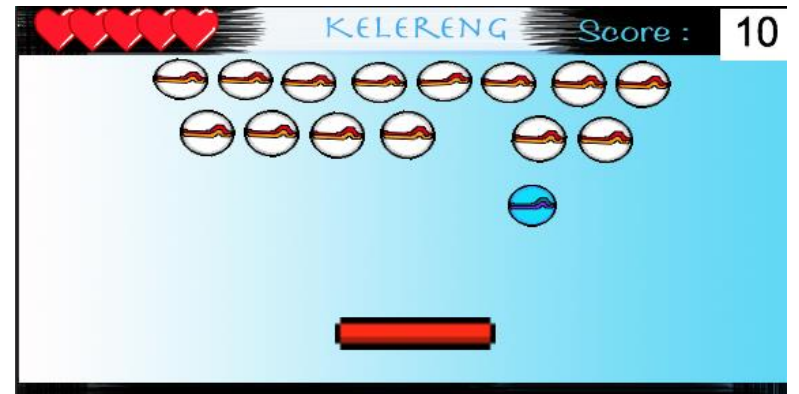

Gambar 29.Tampilan permainan kelereng

\section{Permainan Lompat Batu}

Dan setelah pemain memenangkan Permainan Kelereng, siklus tampilan permainan akan berulang seperti disebutkan pada poin b-e diatas. Lalu akan menuju permainan selanjutnya, yakni : Permainan Lompat Batu. Dalam permainan ini pemain akan ditantang untuk membawa Arjuna melompati batu-batu yang ada, dalam perjalanannya menuju bendera Indonesia. Setelah Arjuna berhasil melampaui rintangan batu dan mencapai bendera Indonesia pemain telah memenangkan permainan dan akan dibawa ke tahap selanjutnya. Tampilan Permainan Lompat Batu ditunjukkan oleh Gambar 30.

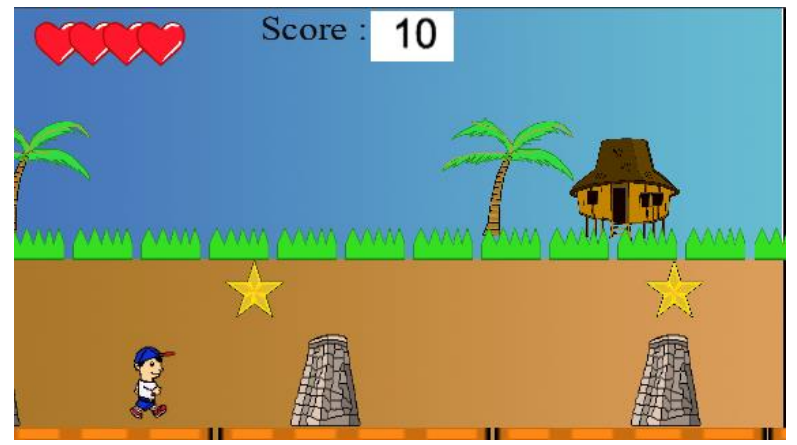

Gambar 30.T ampilan permainan lompat batu

13. Permainan Pilihan Ganda

Dan setelah pemain memenangkan Permainan Lompat Batu, siklus tampilan permainan akan berulang seperti disebutkan pada poin b-e diatas. Lalu akan menuju permainan selanjutnya, yakni : Permainan Pilihan Ganda. Dalam permainan ini pemain akan diberi 10 soal pilihan ganda yang harus dijawab, jawaban benar bernilai poin +10 dan jawaban salah pemain tidak akan mendapatkan poin. Untuk memenangkan permainan ini, diakhir permainan pemain harus mendapatan minimal Score 70 poin. Tampilan Permainan Pilihan Ganda ditunjukkan oleh Gambar 31

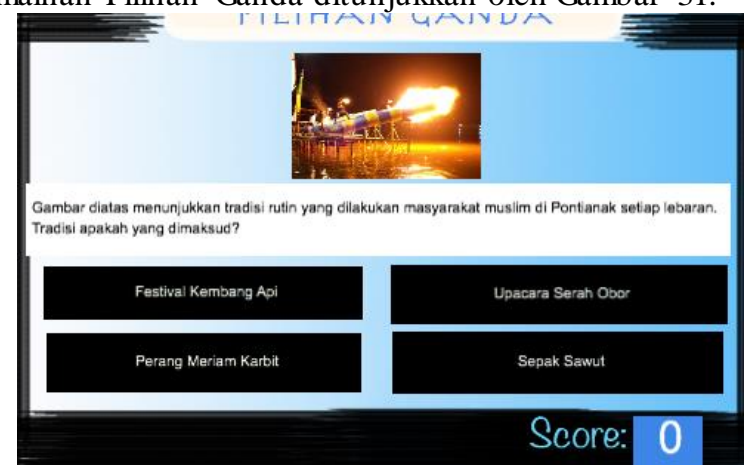

Gambar 31.Tampilan Permainan Pilihan Ganda
14. Permainan Benar Salah

Dan setelah pemain memenangkan Permainan Pilihan Ganda, siklus tampilan permainan akan berulang seperti disebutkan pada poin b-e diatas. Lalu akan menuju permainan selanjutnya, yakni : Permainan Benar/Salah. Dalam permainan ini akan ada kotak-kotak yang turun dari atas layar berisi ciri-ciri khas suatu daerah, pemain diharuskan menyentuh hanya ciri khas yang ada di pulau yang dipilih oleh pemain (Sulawesi/Papua), jika benar skor akan bertambah 10 poin. Permainan akan selesai setelah semua kotak ciri khas turun. Disini permainan selesai, kemudian pemain akan dibawa menuju Cerita Penutup Permainan. Tampilan Permainan Benar/Salah ditunjukkan oleh Gambar 32.

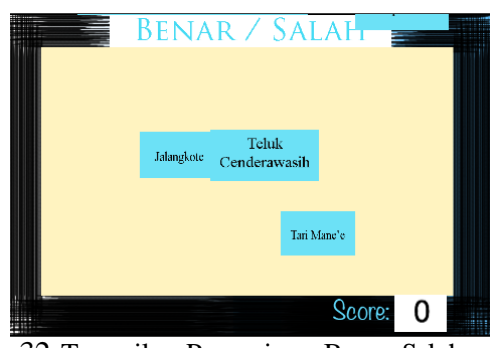

Gambar 32.Tampilan Permainan Benar Salah

15. You Win dan Game Over.

Setelah menyelesaikan suatu permainan, maka akan ditentukan apakah pemain menang atau kalah. Dan tampilan selanjutnya akan menyesuaikan hasil tersebut. Tampilan You Win saat pemain menang ditunjukkan oleh Gambar 33 .

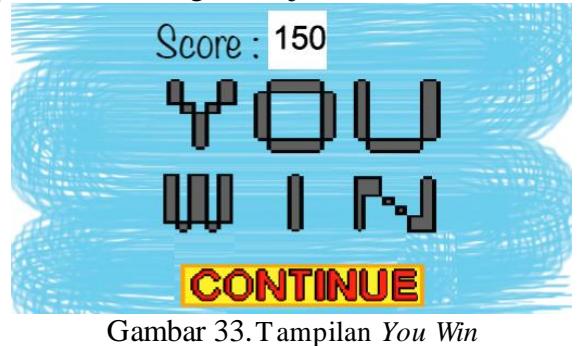

Tampilan Game Over saat pemain kalah ditunjukkan oleh Gambar 34.

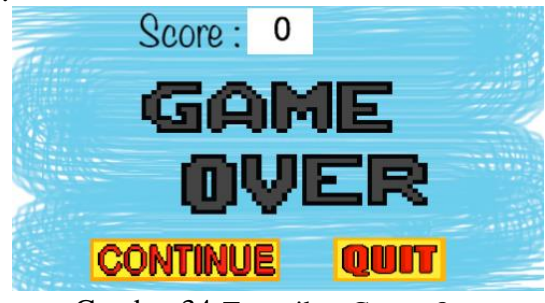

Gambar 34.Tampilan Game Over

16. Cerita Penutup Permainan

Setelah pemain berhasil menyelesaikan Permainan Jelajah Indonesia. Maka akan ditampilkan cerita pendek sebagai penutup. Tampilan Cerita Penutup ditunjukkan oleh Gambar 35 . 


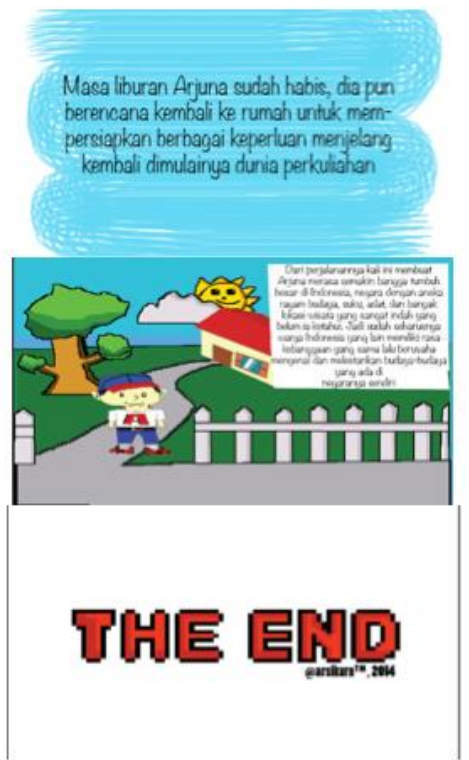

Gambar 35.Tampilan Cerita Penutup Permainan

B. Pengujian aplikasi menggunakan metode black-box

Pengujian aplikasi multimedia pembelajaran interaktif ini dilakukan dengan menggunakan metode black-box. Pengujian ini dilakukan untuk menunjukkan fungsi program yang dibuat tentang cara operasi dan kegunaannya, apakah keluaran data sesuai dengan yang diharapkan. Pengujian ini dilakukan untuk mengetahui apakah masih terjadi kesalahan program atau program sudah berhasil diselesaikan dengan benar.

Pengujian aplikasi dibuat berupa tabel - tabel pengujian black-box dari masing-masing menu yang ada dalam aplikasi. Tabel pengujian pada menu awal permainan ditunjukkan oleh Tabel 1.

Tabel 1. Tabel pengujian menu awal permainan

\begin{tabular}{|l|l|l|c|}
\hline $\begin{array}{c}\text { Nama } \\
\text { Pengujian }\end{array}$ & $\begin{array}{c}\text { Bentuk } \\
\text { Pengujian }\end{array}$ & $\begin{array}{c}\text { Hasil yang } \\
\text { Diharapkan }\end{array}$ & $\begin{array}{c}\text { Hasil } \\
\text { Pengujian }\end{array}$ \\
\hline $\begin{array}{l}\text { Awal } \\
\text { Permainan }\end{array}$ & $\begin{array}{l}\text { Membuka } \\
\text { permainan }\end{array}$ & $\begin{array}{l}\text { Tampilan nama } \\
\text { dan NIM } \\
\text { pengembang, serta } \\
\text { karikatur wajah } \\
\text { pengembang }\end{array}$ & Berhasil \\
\hline $\begin{array}{l}\text { Pengujian } \\
\text { menu Play }\end{array}$ & $\begin{array}{l}\text { Menyentuh } \\
\text { kotak menu } \\
\text { Play }\end{array}$ & $\begin{array}{l}\text { Permainan } \\
\text { dimulai }\end{array}$ & Berhasil \\
\hline $\begin{array}{l}\text { Pengujian } \\
\text { menu } \\
\text { Credits }\end{array}$ & $\begin{array}{l}\text { Menyentuh } \\
\text { kotak menu } \\
\text { Credits }\end{array}$ & $\begin{array}{l}\text { Tampil menu } \\
\text { Credits berisikan } \\
\text { informasi } \\
\text { permainan }\end{array}$ & Berhasil \\
\hline
\end{tabular}

Berikut tabel pengujian pada menu Credits dasar ditunjukkan oleh Tabel 2.

Tabel 2. Pengujian menu Credits.

\begin{tabular}{|l|l|l|c|}
\hline $\begin{array}{c}\text { Nama } \\
\text { Pengujian }\end{array}$ & \multicolumn{1}{|c|}{$\begin{array}{c}\text { Bentuk } \\
\text { Pengujian }\end{array}$} & $\begin{array}{c}\text { Hasil yang } \\
\text { Diharapkan }\end{array}$ & $\begin{array}{c}\text { Hasil } \\
\text { Pengujian }\end{array}$ \\
\hline $\begin{array}{l}\text { Pengujian } \\
\text { tombol } \\
\text { Back }\end{array}$ & $\begin{array}{l}\text { Menyentuh } \\
\text { tombol Back } \\
\text { (panah ke kiri) } \\
\text { pada bagian kanan } \\
\text { bawah. }\end{array}$ & $\begin{array}{l}\text { Kembali pada } \\
\text { tampilan Menu } \\
\text { Awal }\end{array}$ & Berhasil \\
\hline
\end{tabular}

C. Analisis hasil pengujian aplikasi menggunakan Kuesioner Studi kasus dalam pengujian aplikasi ini adalah 20 orang masyarakat umum berusia 14-22 tahun. Dalam pelaksanaannya aplikasi ini dijalankan oleh masingmasing pengguna, dan kemudian diberikan kuesioner kepada pengguna yang digunakan untuk mendapaatkan data responden tentang aplikasi yang dibuat. Kuesioner berisi 10 pertanyaan mengenai tampilan dan fungsionalitas aplikasi. Dari hasil angket yang sudah didapat, kemudian data diolah dan disajikan dalam bentuk table dan diagram batang agar mudah dibaca.

Berikut tabel dan diagram batang hasil data kuesioner yang sudah diolah.

\section{Tampilan permainan}

Hasil data kuesioner tentang tampilan permainan ditunjukkan oleh Tabel 3

Tabel 3. Hasil data kuesioner tampilan permainan

\begin{tabular}{|c|l|c|c|}
\hline No & Pertanyaan & Skor & Keterangan \\
\hline 1 & $\begin{array}{l}\text { Bagaimana } \\
\text { komposisi warna } \\
\text { pada permainan? }\end{array}$ & 77,50 & Cukup baik \\
\hline 2 & $\begin{array}{l}\text { Bagaimana } \\
\text { tampilan } \\
\text { antarmuka dalam } \\
\text { permainan? }\end{array}$ & 81,00 & $\begin{array}{l}\text { Mudah } \\
\text { dipahami }\end{array}$ \\
\hline 3 & $\begin{array}{l}\text { Bagaimana } \\
\text { tampilan teks } \\
\text { yangada didalam } \\
\text { permainan? }\end{array}$ & 84,50 & $\begin{array}{l}\text { Mudah } \\
\text { dibaca }\end{array}$ \\
\hline 4 & $\begin{array}{l}\text { Bagaimana } \\
\text { tampilan karakter } \\
\text { didalam cerita } \\
\text { yangada di } \\
\text { permainan? }\end{array}$ & 80,50 & Sesuai cerita \\
\hline 5 & $\begin{array}{l}\text { Bagaimana } \\
\text { tampilan } \\
\text { permainan ini } \\
\text { secara } \\
\text { keseluruhan? }\end{array}$ & 84,00 & Menarik \\
\hline & Rata-rata & 81,50 & Baik \\
\hline
\end{tabular}


Diagram batang hasil data kuesioner tentang tampilan permainan ditunjukkan oleh Gambar 36 berikut:

\section{Tampilan Permainan}

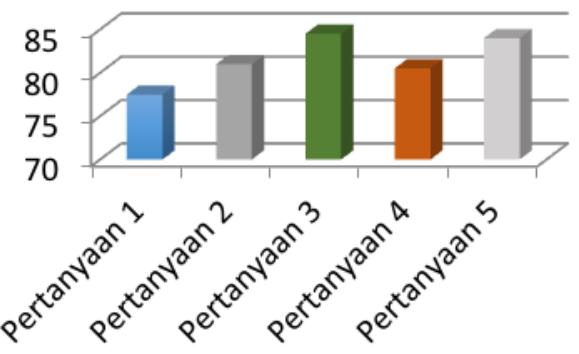

Gambar 36. Diagram batang dari tabel 3

Dari hasil olah data kuesioner tentang tampilan permainan didapatkan skor rata-rata 81,50 atau dapat disimpulkan bahwa tampilan permainan yang dibuat masuk kategori baik.

\section{PENUTUP}

A. Kesimpulan

Kesimpulan dari penelitian Tugas Akhir ini diantaranya sebagai berikut.

1. Berdasarkan hasil pengujian aplikasi menggunakan Black Box Test, seluruh fungsi menu yang ada dalam permainan telah berhasil sesuai dengan fungsinya.

2. Berdasarkan hasil olahan data kuesioner menunjukkan bahwa lebih dari $70 \%$ jawabannya positif, artinya sebagian besar menjawab Baik(B) dan Sangat Baik(SB) pada pertanyaan kuesioner . Rata-rata skor dari seluruh hasil kesioner adalah 81,50 atau temrasuk dalam ketegori "Baik"

3. Permainan Jelajah Indonesia sudah berhasil dikembangkan dan berjalan dengan baik. Kemudian dapat digunakan sebagai media promosi yang mengenalkan ciri khas daerah-daerah di Indonesia.

B. Saran

Saran yang dapat diberikan oleh penulis adalah sebagai berikut.

1. Permainan Jelajah Indonesia hanya mencakup wilayah pulau Jawa, Sumatera, dan Kalimantan, kedepannya mungkin bisa diperluas wilayah cakupan permainan meliputi pulau-pulau lain yang ada di Indonesia.

2. Pada permainan Jelajah Indonesia hanya diberikan lagu sebagai suara latar belakang permainan, diharapkan dilengkapi dengan efek suara pada saat permainan berjalan, sehingga permainan lebih menarik.

3. Latar belakang cerita permainan Jelajah Indonesia sangat pendek dan sederhana. Kedepannya mungkin latar belakang cerita bisa lebih dikembangkan dan ditambahkan karakter atau tokoh baru yang mendukung cerita agar lebih kompleks.

\section{DAFTAR PUSTAKA}

[1] Abadi, Rizki. Gadget Antara Kebutuhan dan Gaya.Hidup.https://kreditgogo.com/artikel/Keuanga n-dan-Anda/Gadget-Antara-Kebutuhan-dan-GayaHidup.html.30 November 2014

[2] Malaney, R. A. 2006. Mobile games, GPS, and quality of service in J2ME. Journal of Game Development, 1, 4, 29

[3] Xu, C. 2008. A New Communication Framework for Networked Mobile Games. Journal of Software Engineering and Application, 1, 1, 20.

indahf. Pengertian dan Definisi Indonesia Menurut Para

Ahli.http://carapedia.com/pengertian_definisi_indon esia_menurut_para_ahli_info511.html. 30 November 2014

[5] Salen, K. and E.Zimmerman. 2003. Rules of Play : Game Design Fundamentals. MIT Press, Massachusetts.

[6] Setyaningsih, R. Yuliana., et al., Game Matematika Untuk Pembelajaran Murid SD, Makalah Proyek Akhir, Institut Teknologi Sepuluh Nopember, Surabaya, 2010.

Yudhanto, Adi Prasetyo,. Perancangan Promosi Edu-Games Melalui Event, Skripsi S-1, Jurusan Desain Komunikasi Visual, Universitas Komputer, Bandung, 2010

[8] Ranjabar, Jacobus. 2006. Sistem Sosial Budaya Indonesia: Suatu Pengantar. Bogor: Ghalia Indonesia.

[9] ditindib. 77 karya budaya ditetapkan sebagai Warisan Budaya Takbenda Indonesia tahun 2013. http://kebudayaan.kemdikbud.go.id/ditindb/2014/03/ 05/77-karya-budaya ditetapkan-sebagai-warisanbudaya-takbenda-indonesia-tahun-2013/.20 September 2014

[10] Vaughan, Tay. 2004. Multimedia: Making It Work. Edisi keenam. Yogyakarta : Andi

[11] Binanto, Iwan. 2010. Multimedia Digital - Dasar Teori dan Pengembangannya. Yogyakarta: Andi.

[12] Guerineau, David. 2012. Learn GameSalad for iOS Game Development for iPhone, iPad, and HTML5. New York: Apress

[13] Chandra, Victor. 2013. Pintar Pemrograman Aplikasi iPhone \& iPad. Yogyakarta: Andi. 
[14] Goldstein, Neal. Paris Buttfield- Addison. Jon Manning. 2011.iPhone \& iPad Game Development For Dummies. Indianapolis : Wiley Publishing,Inc.

[15] Apple. 2010. iOS Technology Overview. California: Apple.

[16] Al-Bahra bin Ladjamudin. 2005. Analisis dan Desain Sistem Informasi. Yogyakarta : Graha Ilmu.

[17] Widada.Flowchart.http://widada.staff.gunadarma. ac.id/Downloads/files/13075/FLOWCHART.doc.20 September 2014
[18] Vicky. Mengenal software editing foto Adobe Photoshop.http://belajar-komputermu.com/mengenal -software-editing-foto-adobe-photoshop/. 24 September 2014.

[19] ---. Pixen. http://pixenapp.com. 24 September 2014.

[20] ---.Overview. https://www.propellerheads.se/ products/figure/manual/introduction/. 24 September 2014. 